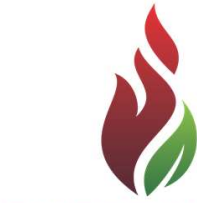

SUSTENERE

Publishing Corporation

\section{EXTRATOS VEGETAIS DE PLANTAS DANINHAS CONTRA O PULGÃO APHIS CRACCIVORA KOCH 1854, NO FEIJÃO VIGNA UNGUICULATA (L.) WALP}

\section{RESUMO}

O feijão-caupi (Vigna unguiculata (I.) Walp.) é uma leguminosa rústica dos trópicos semi-árido, úmido e subúmido. É cultivado principalmente por pequenos agricultores nas regiões nordeste e norte do país onde consiste da principal fonte proteica vegetal para a população, e uma das principais alternativas sociais e econômicas de suprimento alimentar e geração de emprego, especialmente para as populações rurais. Dentre os fatores limitantes ao seu cultivo destacam-se as pragas e, dentre estas, o pulgão Aphis craccivora Koch, 1854 (Hemiptera: Aphididae), que, além de causar danos diretos sugando sua seiva, ainda é responsável pela transmissão de vírus. Este trabalho visou avaliar a atividade inseticida de extratos vegetais obtidos de plantas daninhas contra o pulgão preto no feijão caupi em condições de laboratório. As plantas, selecionadas por meio de estudos etnobotânicos e quimiossistemáticos, foram secas e reduzidas a pó, sendo os extratos botânicos obtidos a partir de soluções etanólicas por percolação a frio, com remoção posterior do solvente por destilação à pressão reduzida. Os pulgões foram coletados em ramos novos de feijão caupi infestado, na área experimental da universidade. $O$ delineamento utilizado foi inteiramente casualizado, utilizando-se 10 espécies de plantas daninhas para obtenção dos extratos em diferentes concentrações 500, $1000,1500,2000$ PPM. As plantas mostraram um elevado poder inseticida superior a $60 \%$ de taxa de mortalidade do pulgão preto, exceto para a tiririca. Assim as plantas daninhas podem ser utilizadas para a obtenção de inseticidas naturais ou para o isolamento dos princípios ativos que permitam a síntese de novos produtos fitossanitários.

PALAVRAS-CHAVES: Plantas Inseticidas, Extratos Botânicos, Inseticidas Naturais.

\section{EXTRACTS WEED PLANT AGAINST BEDBUG APHIS CRACCIVORA KOCH 1854, THE BEAN VIGNA UNGUICULATA (L.) WALP}

\section{ABSTRACT}

The cowpea (Vigna unguiculata (L.) Walp.). Is a legume rustic tropical semi-arid, humid and subhumid. It is mainly grown by small farmers in the northeastern and north of the country is the main protein source for the plant population, and a major social and economic alternative food supply and employment generation, especially for rural populations. Among the limiting factors to its cultivation there are the pests and, among these, the aphid Aphis craccivora Koch (Hemiptera: Aphididae), which, besides causing direct damage by sucking their sap, it is still responsible for the transmission of viruses. This study evaluated the insecticidal activity of plant extracts obtained from weeds against the black cowpea aphid in laboratory conditions. Plants were selected by means of studies and ethnobotanical quimiossistemáticos, dried and reduced to powder, with botanical extracts obtained from ethanolic solution by the percolation cold, the solvent then removed by distillation at reduced pressure. Aphids were collected in new shoots of cowpea infested at the site of the university. The experimental design was randomized, using 10 weed species to obtain the extracts at different concentrations 500, 1000, 1500, 2000 PPM. The plants showed a high insecticidal power greater than $60 \%$ mortality of the aphid black, except for the weed. Thus weeds can be used for obtaining natural insecticides or for the isolation of the active principles that allow the synthesis of new pesticides.

KEYWORDS: Plant Insecticides; Botanical Extracts; Natural Insecticides.
Revista Ibero-Americana de

Ciências Ambientais, Aquidabã, v.6, n.2, Jun, Jul, Ago, Set, Out, Nov 2015.

ISSN 2179-6858

\section{SECTION: Articles}

TOPIC: Ecologia e Biodiversidade

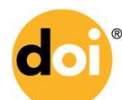

DOI: 10.6008/SPC2179-6858.2015.002.0005

\section{Carlos Alberto Batista Santos \\ Universidade do Estado da Bahia, Brasil http://lattes.cnpq.br/0024544164324027 cacobatista@yahoo.com.br}

Ana Paula Miranda Silva Universidade do Estado da Bahia, Brasil http://lattes.cnpq.br/3045746471289318 silvascher@hotmail.com

Received: 07/05/2015

Approved: 21/10/2015

Reviewed anonymously in the process of blind peer.

Referencing this:

SANTOS, C. A. B.; SILVA, A. P. M.. Extratos vegetais de plantas daninhas contra o pulgão aphis craccivora koch 1854, no feijão vigna unguiculata (I.) walp. Revista Ibero-Americana de Ciências Ambientais, Aquidabã v.6, n.2, p.69-75, 2015. DOI: http://dx.doi.org/10.6008/SPC21796858.2015 .002 .0005 


\section{INTRODUÇÃO}

As plantas são seres vivos complexos e, como tais, apresentam um metabolismo extraordinário, que leva à produção de uma grande variedade de substâncias químicas. Algumas dessas substâncias como as proteínas, os lipídios, os carboidratos e os ácidos nucléicos são comuns a todos os seres vivos e usados no crescimento, na reprodução e na manutenção dos vegetais. No entanto, um número elevado de compostos químicos produzidos pelos vegetais serve a outros propósitos.

Poser \& Mentz (2001) comentam sobre essas substancias, listando os pigmentos flavonóides, antocianinas e betalaínas e os óleos essenciais monoterpenos, sesquiterpenos e fenilpropanóides que atraem polinizadores, e os taninos, lactonas sesquiterpênicas, alcalóides e iridóides. Além de apresentarem sabores desagradáveis, essas substâncias, funcionam como dissuasórios alimentares e permitem à planta se proteger da herbívora, pois apresentam toxicidade e provocam irritação.

Os inseticidas botânicos surgiram devido à necessidade de se dispor de alternativas ao controle químico de insetos-praga nos cultivos agrícolas, especialmente em olerícolas, reduzindo ou eliminando os problemas de contaminação ambiental, resíduos nos alimentos, efeitos prejudiciais sobre organismos benéficos e aparecimento de insetos resistentes. Alguns autores já comprovaram a eficiência inseticida de vários extratos vegetais, como Cabral et al. (1996) e Valladares et al. (1997) que apontam o extrato de cinamomo como um dos compostos naturais mais promissores para uso como inseticida natural. Oliveira et al. (1995) trabalhando com extrato de pimenta do reino sobre o Sitophilus zeamais, mostraram que a população desse inseto-praga foi controlada em 90\%. Germano (1997), estudando o emprego de inseticidas naturais no tratamento de sementes de Vigna unguiculata, encontrou que o extrato bruto de casca de laranja, foi eficiente no controle de pragas e na manutenção da qualidade fisiológica das sementes armazenadas.

O uso de extratos vegetais surge como uma opção para o manejo integrado de pragas e associado a outras práticas, pode contribuir para a redução de doses e aplicações de inseticidas químicos sintéticos, que apresentam problemas aos organismos benéficos e ao meio ambiente. $\mathrm{O}$ feijão-caupi se constitui numa das principais culturas agrícolas nas regiões Norte e Nordeste do Brasil, sendo um dos principais componentes da dieta alimentar, especialmente na zona rural, assumindo grande importância social e econômica, principalmente, para as camadas mais carentes da população.

É uma excelente fonte de proteínas (23-25\%) e apresentam todos os aminoácidos essenciais, carboidratos, vitaminas e minerais, além de possuir grande quantidade de fibras dietéticas, baixos índices de gordura e não conter colesterol (Cardoso \& Barreto 1997). Pelo seu valor nutritivo, o feijão-caupi é cultivado principalmente para a produção de grãos, secos ou verdes, visando o consumo humano in natura, na forma de conserva ou desidratado. Além disso, 
o caupi também é utilizado como forragem verde, feno, ensilagem, farinha para alimentação animal e, ainda, como adubação verde e proteção do solo.

Segundo Miranda et al. (1996) mesmo sendo considerada uma cultura compatível com as condições ecológicas locais, apresenta baixa produtividade, tanto no sistema solteiro como no consorciado, e uma das causas apontadas como limitantes a produtividade da cultura segundo Moraes \& Ramalho (1980) é a agressividade do piolho-negro (Aphis craccivora Koch), que se alimenta sugando a seiva floemática, transmitindo vírus e produzindo o mela, substância açucarada que serve de substrato para o desenvolvimento do fungo Capnodium sp. (COSTA et al. 2010).

A ação de sucção dos pulgões ainda provoca o encarquilhamento das folhas e a deformação dos brotos (GALLO et al. 2002), as plantas atacadas ficam debilitadas em virtude da grande quantidade de seiva retirada e de toxinas injetadas. O pulgão-preto é, normalmente, controlado com inseticidas sintéticos, o mau uso destes pode ocasionar efeito negativo ao ambiente, como a mortalidade dos organismos benéficos. Esse problema pode ser amenizado por substâncias extraídas de plantas, na qualidade de inseticida, tendo vantagens sobre os sintéticos, pois os inseticidas naturais são obtidos de recursos renováveis e rapidamente degradáveis e o desenvolvimento da resistência dos insetos a essas substâncias é lento, não deixam resíduos em alimentos, além do baixo custo de produção (Roel 2001).

Os termos 'plantas invasoras', 'ervas más', 'plantas daninhas', 'ervas daninhas', 'plantas silvestres', 'plantas ruderais', 'inços', 'mato' 'juquira', etc., tem sido indiferentemente empregados nas literaturas agrícola e botânica brasileira (Lorenzi 2006). As plantas daninhas, para efeito de estudo, podem ser classificadas de várias maneiras dependendo do interesse. A mais comum é aquela que se baseia na duração de seu ciclo vital e que as classifica em 'plantas anuais', "bianuais' e 'perenes'. Entre as espécies anuais estão à maioria das plantas infestantes das grandes culturas e compreendem aquelas que germinam e completam o ciclo até a maturação das sementes dentro da mesma estação de crescimento (60 a 140 dias), este conceito foi utilizado como referencia para este trabalho.

\section{MATERIAIS E MÉTODOS}

O trabalho foi desenvolvido nos laboratórios de Entomologia, Hidráulica e Inforquímicos da Universidade do Estado da Bahia, no Departamento de Tecnologia e Ciencias Sociais, Campus III. As plantas utilizadas foram selecionadas por meio de estudos etnobotânicos e quimiossistemáticos. O experimento foi composto por um grupo de plantas denominadas daninhas (Quadro 1). No total foram utilizadas 10 espécies plantas daninhas, das quais foram produzidos extratos em quatro concentrações diferentes (500, 1000, 1500 e 2000 PPM) e dois controles, água destilada e Dimetil Sulfóxido (DMSO), cada concentração fora composta de quatro repetições. 
Quadro 1: Espécies selecionadas - plantas daninhas.

\begin{tabular}{l|l}
\hline Nome comum & Nome científico \\
\hline Cansanção & Cnidoscolus urens L., \\
\hline Canudo & Ipomoea fistulosa Mart. \\
\hline Cardo santo & Argemone mexicana L. \\
\hline Chumbinho & Lantana camará L. \\
\hline Cravo de defunto & Tagetes minuta L. \\
\hline Lã de seda & Calotropis procera Aiton. \\
\hline Leiteira & Euphorbia heterophylla L. \\
\hline Mamona & Ricinus communis L. \\
\hline Melão de São Caetano & Momordica charanthia L. \\
\hline Tiririca & Cyperus rotundus L. \\
\hline
\end{tabular}

A coleta do material vegetal para produção de extratos vegetais foi realizada na área experimental da UNEB/DTCS (Latitude: 09 24' 50" S; Longitude: 40 30 10' W; Altitude: 368m). Foram utilizadas as folhas das diferentes espécies selecionadas, principalmente em função da abundância. Na ocasião da coleta, aspectos fitossanitários das folhas foram observados, dando preferência às folhas com bom estado de conservação.

Para realização das coletas fez-se uso de tesoura e alicate de poda, bandejas de 20 litros e luvas de couro. Após a coleta das espécies vegetais estas foram transportadas para o laboratório onde foram separadas, identificadas e postas para secar a temperatura ambiente. A cada coleta de folhas, foi realizada uma coleta de um ramo fértil, de cada planta utilizada no experimento. Esses ramos foram prensados, secos e identificados com o objetivo de direcioná-los para o Herbarium da UNEB/DTCS. Após sete dias da coleta do cada material vegetal, estas totalmente secas, passaram por triturador de malha de $5 \mathrm{~mm}$ resultando em um pó vegetal acondicionadas em recipientes hermeticamente fechados e identificados. Em seguida parte desse pó vegetal, aproximadamente 300 gramas, foram colocados em recipiente de vidro com álcool $\left(92,8^{\circ}\right)$, posteriormente vedado, agitado e posto para descansar.

Após 24 horas, essa solução foi coada, e os líquidos resultantes desse processo colocados em balão e levados ao rotoevaporador. Os extratos botânicos foram obtidos a partir de soluções etanólicas por percolação a frio, com remoção posterior do solvente por destilação à pressão reduzida, ou seja, remoção do solvente (álcool) e depósito do soluto no balão, o qual foi drenado para um recipiente fixo devidamente higienizado e identificado e colocados em ambiente aberto e ventilado para que os extratos secassem totalmente Em seguida os recipientes com os extratos secos eram vedados com papel filme PVC e armazenados. Para pesagem utilizou-se balança de precisão e os extratos foram pesados nas diferentes concentrações (Tabela 1). Foi adicionado 1\% de Dimetil Sulfóxido-DMSO o que corresponde a 1 (um) $\mathrm{ml}$ de DMSO para solubilizar os extratos, por fim os recipientes com extratos foram levados para o banho de ultra som por 24 horas para ser homogeinizado.

Para finalizar os recipientes com os extratos foram retirados do banho de ultra som e as soluções transferidas para recipientes de $150 \mathrm{ml}$, em seguida foi adicionada $99 \mathrm{ml}$ de água destilada em cada recipiente e estes eram vedados com papel filme PVC, dessa forma foi obtida uma solução com volume total de $100 \mathrm{ml}$. Os pulgões apteros foram coletados na horta 
experimental da UNEB/DTCS, concentros em ramos novos e frutos do feijoeiro. Após coleta dos ramos infestados, fez-se também coleta de folhas limpas e levadas para laboratório onde foram iniciados os testes em placas de Petri, forradas com papel toalha para receberem pedaços de folhas. Cada tratamento experimental (10 plantas) constou de quatro concentrações diferentes e cada concentração foi composta de quatro repetições com duas testemunhas (água destilada e DMSO). Em cada placa foram depositados lotes de 10 pulgões manipulados com pinceis e pinças, estes eram pulverizados com as soluções e vedados com papel filme PVC, em seguida eram colocadas em câmaras BOD com delineamento inteiramente casualizado.

Tabela 1: Relação de peso e concentração utilizados na pesagem dos extratos.

\begin{tabular}{l|l|l|l|l}
\hline Unidades de Medidas & \multicolumn{4}{l}{ Relação de Peso e Concentração } \\
\hline Peso em Grama & 0,050 & 0,100 & 0,150 & 0,200 \\
\hline Concentração em PPM & 500 & 1000 & 1500 & 2000 \\
\hline Tratamentos & C1 & C2 & C3 & C4 \\
\hline
\end{tabular}

\section{RESULTADOS}

As plantas daninhas selecionadas e cujos extratos foram testados apresentaram dados satisfatórios como planta inseticida, com exceção da Tiririca (Tabela 2). O melhor resultado na concentração de 500 e 1000 PPM foi o extrato da planta Chumbinho, que também foi o melhor na concentração de 1500 PPM juntamente com o Melão São Caetano. A maior porcentagem de mortalidade na concentração de 2000 PPM foi do Melão de São Caetano. A planta Tiririca apresentou o menor índice de mortalidade (inferior a 50\%) nas diferentes concentrações (Gráfico $1)$.

Tabela 2: Atividade inseticida das plantas daninhas testadas no laboratório da UNEB/DTCS.

\begin{tabular}{|c|c|c|c|c|}
\hline \multirow{2}{*}{ PLANTA DANINHA } & \multicolumn{4}{|c|}{ Taxa de Mortalidade (\%) } \\
\hline & 500 ppm & 1000 ppm & 1500 ppm & 2000 ppm \\
\hline Cansanção & 65 & 62,5 & 62,5 & 67,5 \\
\hline Canudo & 70 & 72,5 & 72,5 & 75 \\
\hline Cardo santo & 65 & 65 & 67,5 & 67,5 \\
\hline Chumbinho & 75 & 77,5 & 80 & 82,5 \\
\hline Cravo de defunto & 72,5 & 70 & 75 & 77,5 \\
\hline Lã de seda & 72,5 & 70 & 75 & 80 \\
\hline Leiteira & 65 & 67,5 & 70 & 70 \\
\hline Mamona & 67,5 & 65 & 67,5 & 70 \\
\hline Melão S. Caetano & 72,5 & 72,5 & 80 & 85 \\
\hline Tiririca & 42,5 & 45 & 42,5 & 47,5 \\
\hline
\end{tabular}




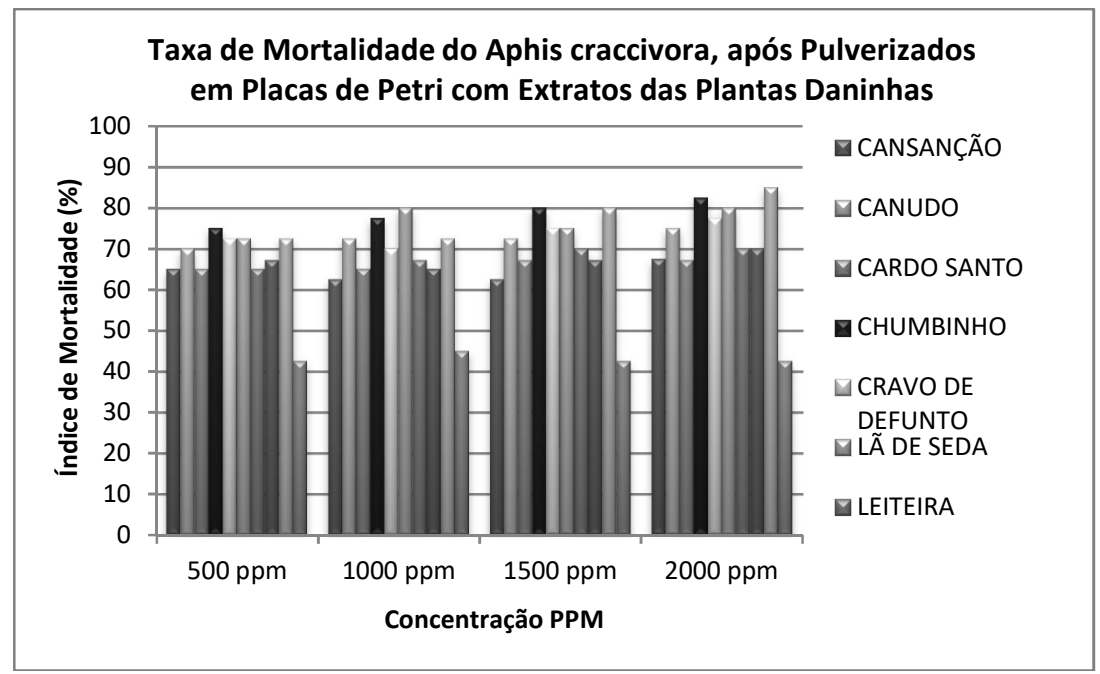

Gráfico 1: Taxa de mortalidade do pulgão preto tratadas com extratos de plantas daninhas em diferentes concentrações.

\section{CONCLUSÕES}

As plantas daninhas apresentaram dados satisfatórios como plantas inseticidas, com taxas de mortalidade superiores a $60 \%$, nas concentrações testadas, com exceção da tiririca cujos extratos em diferentes concentrações se manteve numa faixa de $42,5 \%$ a $47,5 \%$ de letalidade contra o pulgão preto do feijoeiro. Recomenda-se a produção de extratos de chumbinho e melão de são caetano, por estas apresentarem melhor eficiência como inseticidas naturais nos testes realizados. Os extratos devem ser testados em casa de vegetação e em campo para que o conhecimento de sua eficiência seja preciso.

As plantas daninhas por se constituírem num recurso natural abundante e de fácil acesso, podem e devem ser utilizadas para a obtenção de inseticidas naturais como alternativa aos inseticidas sintéticos, tendo como vantagens o baixo custo de produção tornando-os economicamente mais acessíveis aos pequenos produtores, além do efeito não cumulativo nos alimentos e no ambiente. A produção de extratos vegetais deve ser utilizada também para o isolamento dos princípios ativos que permitam a síntese de novos produtos fitossanitários.

\section{REFERÊNCIAS}

CABRAL, M. M. O.; GARCIA, E. S.; REMBOLD, H.. Antimoulting activity in Brazilian Melia azedarach. Memórias do Instituto Oswaldo Cruz. Rio de Janeiro, v.91, n.1, p.117-118, 1996.

CARDOSO, M. O.; BARRETO, J. F.. Hortaliças não convencionais da Amazônia. Brasília: Empresa Brasileira de Pesquisa Agropecuária, 1997.

COSTA, J. V. T. A.; BLEICHER, E.; CYSNE, A. Q.; GOMES, F. H. T.. Óleo e extrato aquoso de sementes de nim, azadiractina e acefato no controle do pulgão-preto do feijão-de-corda. Pesquisa Agropecuária Tropical. Goiânia, v.40, n.2, p.238-241, 2010. 
GALLO, D.; NAKANO, O.; NETO, S. S.; CARVALHO, R.; PEREIRA, L.; BAPTISTA, G. C.; FILHO, E. B.; PARRA, J. R. P.; ZUCCHI, R. A.; ALVES, S. B.; VENDRAMIM, J. D.; MARCHINI, L. C.; LOPES, J. R. S.; OMOTO, C.. Entomologia Agrícola. Piracicaba: FEALQ, 2002.

GERMANO, L. M. A. R.. Emprego de produtos naturais no tratamento de sementes de feijão macassar (Vigna unguiculata (L) Walp), acondicionadas em três microregiões do Estado da Paraíba.

Dissertação (Mestrado em Agronomia) - Universidade Federal da Paraíba, Areia, 1997.

LORENZI, H.. Manual de identificação e de controle de plantas daninhas: plantio direto e convencional. Nova Odessa: Instituto Plantarum, 2006.

MIRANDA, P.; COSTA, A. F.; OLIVEIRA L. R.; TAVARES, J. A.; PIMENTEL, M. L.; LINS, G. M. L.. Comportamento de cultivares de Vigna unguiculata (L) Walp. nos sistemas solteiro e consorciado. IV - tipos ereto e semiereto. Pesquisa Agropecuária Pernambucana, Recife, v.9, n.2, p.95-105, 1996.

MORAES, G. J.; RAMALHO, F. S.. Alguns insetos associados a Vigna unguiculata Walp. no Nordeste. Petrolina: EMBRAPA-CPATSA, 1980.

OLIVEIRA, M. M.; GOLDFARB, A. C.; OLIVEIRA, E. C. S.. Efeitos dos extratos etanólicos de Piper sp (piperacea) e Camelia sinensis sobre o inseto praga Sitophilus zeamais (coléoptero curculionoidae). In: REUNIÃO ANUAL DA SBPC. 47. Anais. São Luis: Sociedade Brasileira para o Progresso da Ciência, 1995.

POSER, G. L.; L. A. M.. Diversidade biológica e sistemas de classificação. Porto Alegre: Universidade Federal do Rio Grande do Sul, 2001.

ROEL, A. R.. Utilização de plantas com propriedades inseticidas: uma contribuição para o Desenvolvimento Rural Sustentavel. Revista Internacional de Desenvolvimento Local, Campo Grande, v.1, n.2, p.43-50, 2001.

VALLADARES, G.; DEFAGO, M. T.; PALACIOS, S.. Laboratory evaluation of Melia azedarach (Meliaceae) extracts against the Elm Leaf Beetle (Coleoptera: Chrysomelidae). Journal of Economic Entomology, Annapolis, v.90, n.3, p.747-750, 1997. 